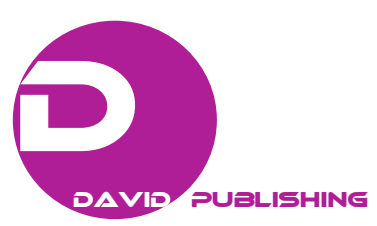

\title{
Parasites of Anisakidae Family-Geographical Distribution and Threat to Human Health
}

Ewa Bilska-Zając, Mirosław Różycki, Ewa Chmurzyńska, Jacek Karamon, Jacek Sroka, Maciej Kochanowski, Paweł Kusyk and Tomasz Cencek

Department of Parasitology and Invasive Diseases, National Veterinary Research Institute in Puławy, Partyzantów Avenue 57, Puławy 24-100, Poland

\begin{abstract}
Nematodes of the Anisakidae family are important parasites that can cause anisakiasis - human parasitic infection of gastrointestinal tract. Allergic symptoms can arise as secondary immune response after infection by living parasite. In the life cycle of these parasites, intermediate, definitive and paratenic hosts (fish) might occur. In most cases, human anisakiasis is caused by consumption of fish which are infected with the larvae of the Anisakidae family. The purpose of the article was to assess the definitive host, the geographical spread of the parasites and the risk associated with consumption of raw fish and fishery products. Furthermore, this article describes symptoms and treatment of anisakiasis and kinds of preventive measures that can be taken to prevent anisakiasis.
\end{abstract}

Key words: Larvae of Anisakidae family, Anisakis, Pseudoterranova decipiens, anisakiasis.

\section{Introduction}

Anisakiasis is parasitic zoonosis caused by larval forms of nematodes of the Anisakidae family. Humans become infected by ingesting raw or undercooked meat of marine fish or cephalopods containing third-stage (L3) larvae of these nematodes (usually Anisakis simplex s.s., Anisakis pegreffii and Pseudoterranova decipiens). Live larvae can cause gastrointestinal mucositis, haemorrhages, granulomas and other symptoms by damaging gastrointestinal tract. Gastro-allergic anisakiasis (hypersensitivity to parasite allergens) is more common than gastrointestinal anisakiasis caused by the presence of parasites in digestive tract. The genus Anisakis has the greatest importance in the Anisakidae family because of high pathogenicity of the L3 larvae [1-5]. The characteristic of the parasite, geographic distribution (including individual species) and their pathogenicity and risk will be presented in this paper.

Corresponding author: Mirosław Różycki, Ph.D., research fields: parasitology and invasive diseases. E-mail: mrozycki@piwet.pulawy.pl.

\section{Life cycle}

The nematode Anisakis spp. has a complex life cycle. Sexually mature nematodes are found in the stomachs of marine mammals. The fertilized females of nematodes lay eggs into the digestive tract of the definitive host. The eggs are passed in the feces to the water. The eggs become embryonated in water and first stage larvae are formed in the eggs. The larvae moult and become to be second-stage (L2) larvae. In this form, the larvae hatch from the eggs. Released from eggs, free-swimming L2 larvae are ingested by crustaceans. The development of larvae in eggs requires a suitable temperature $\left(5-7{ }^{\circ} \mathrm{C}\right)$. The eggs hatch in 20-27 d. This stage is invasive for the intermediate hosts which usually are crustaceans (mainly from the cluster crustacea). Inside these hosts, the larvae moult into third-stage (L3) larvae. Transmission to other hosts is possible via ingestion of infected crustaceans. Fish and cephalopods appear to be paratenic hosts as the development from second to third stage occurs in crustaceans. In their bodies, L3 larva locates mainly in the peritoneum and the liver 
capsule or between gonads. Once the fish have been caught, as a result of environmental changes (death of the fish, the increase of temperature and change of $\mathrm{pH}$ ) prior to evisceration, Anisakis spp. larvae migrates from the body cavity into the fish muscle, which dramatically increases the risk of infection to human. Pseudoterranova spp. larvae are also able to intravitally migrate into the muscle $[1,2,6]$.

\section{Identification of Anisakidae Larvae}

The most common fish nematodes of the Anisakidae family are parasites belonging to the genera Anisakis, Pseudoterranova, Contracaecum, and Phocascaris. The species or genus identification of the Anisakidae larvae using microscopic observation on the basis of several morphological characteristics is performed. During examination, the morphology of cuticula, oesophagus, ventriculus and excretory pore are taken into account. The developmental stage of larvae, which have been detected in fish, as well as geographical distribution and host range are also important [3]. The morphological differentiation is not as accurate as genetic analysis. The developed molecular techniques based on the study of genetic markers, particularly COX-2 gene and the ITS1 and ITS2, are perfect for precise distinction of species of the genus Anisakis or Pseudoterranova. In Ref. [4], Anisakis species are divided into two clades. In one of them, there are Anisakis pegreffii, Anisakis simplex s.s., Anisakis simplex C, Anisakis typica, Anisakis ziphidarum; while in the other one, there are Anisakis physeteris, Anisakis paggiae and Anisakis brevispiculata [4]. For species identification of Anisakidae larvae, biochemical analysis of allozyme can be applied, allowing species differentiation of Contracaecum and Phocascaris [7].

\section{Distribution}

The strict geographic distribution of these species is very difficult to determine. However, studies on selected fisheries areas allow to identify where the parasite species occur most frequently and where definitive hosts were most commonly reported:

- The most widespread species of the genus Anisakis is Anisakis simplex s.s.. The parasite occurs mainly in the Northern waters of the Atlantic Ocean and the Pacific Ocean. The most frequent definitive hosts are Minke whales (Balaenoptera acutorostrata), common Dolphins (Delphinus delphis), Pilot whales (Globicephala melaena), White-beaked dolphin (Lagenorhynchus albirostris), Killer whales (Orcinus orca) and Striped dolphin (Stenella coeruleoalba). The species was also found in Gray seals (Halichoerus grypus) and Harbor seals (Phoca vitulina) from the Baltic Sea;

- Anisakis pegreffii was detected more rarely than Anisakis simplex s.s. This species occurs mainly in the Mediterranean Sea and the waters of the Southern Atlantic Ocean. Parasites are quite common in dolphins (Delphinus delphis), Cuvier's beaked whale (Ziphius cavirostris) and common Bottlenose dolphin (Tursiops truncatus);

- Anisakis simplex C occurs in the Southern waters of the Atlantic Ocean and Northern Pacific Ocean. This species was usually found in False killer whale (Pseudorca crassidens) and Cuvier's beaked whale (Ziphius cavirostris);

- Anisakis ziphidarum was found mainly in the Mediterranean Sea and the Southern waters of the Atlantic Ocean similar Anisakis pegreffi. The most common definitive hosts are true's Beaked whale (Mesoplodon mirus), Strap-toothed whale (Mesoplodon layardii), the Cuvier's beaked whale (Ziphius cavirostris) and all species of the Ziphiidae family;

- Anisakis sp. A is a species that has only been detected of the coast of Madeira and Spain [8]. It was found only in Blainville's beaked whale (Mesoplodon densirostris);

- Anisakis typica is a species founded in the warm waters of the Atlantic Ocean. This species was found 
in Tucuxi (Sotalia fluviatilis), Striped dolphin (Stenella coeruleoalba), Pantropical spotted dolphin (Stenella attenuata), Spinner dolphins (Stenella longirostris), Rough-toothed dolphin (Steno bredanensis) and Fraser's dolphin (Lagenodelphis Hosei);

- Anisakis physeteris, like Anisakis pegreffii and Anisakis ziphidarum, occurs in the Mediterranean Sea and the Atlantic Ocean. The most common definitive hosts are Pygmy sperm whale (Kogi breviceps), Dwarf sperm whale (Kogi sima), Cachalot (Physeter macrocephalus) and rarely Cuvier's beaked whale (Ziphius cavirostris);

- Anisakis brevispiculata also occurs in the Mediterranean Sea and the waters of the Central Atlantic Ocean. Definitive hosts are the same as in the case of Anisakis physeteris (Kogi breviceps, Kogi sima and Physeter macrocephalus);

- Anisakis paggiae was detected in Pygmy sperm whale (Kogi breviceps) and Dwarf sperm whales (Kogi sima) in the Atlantic Ocean, particularly in its central part;

- Anisakis schupakovi was detected endemic in the Caspian Sea only in Caspian seals (Phoca caspica) [9].

The larvae of Anisakis spp. are commonly found in marine fish, which are paratenic hosts for these parasites, all over the world, especially in the waters of the Northern Hemisphere. It is estimated that $40 \%-80 \%$ of marine fish are infected by Anisakis spp. larvae [10]. Because these parasites are often observed in Herring and they are called "herring worms". The invasion may also occur in such species of fish, as Cod (Gadus morhua), Mackerel (Scomber scombrus) (Fig. 1), Salmon (Salmonidae), Garfish (Belone belone) and many others. Anisakis larvae may be found also in fish living in brackish (salt and fresh water mix) waters, like Rainbow trout (Oncorhynchus mykiss) [11]. For example, the presence of Anisakis spp. larvae was noted in Zander (Sander lucioperca) coming from the Vistula Lagoon [12]. In total, the larvae of nematodes were founded in $12 \%$ of these fishes.
Food and Agriculture Organization of the United Nations (FAO) prepare a report, which provides information on the prevalence of Anisakis simplex larvae of several species of high economic importance (Table 1). In some cases, $100 \%$ of samples from wild fishes were infected with Anisakis simplex larvae. However, parasites were not found in any fish from aquafarming [13]. A retrospective analysis of literature data on Anisakidae prevalence suggests that their life cycle depend on water salinity and the presence of small shrimp-like crustaceans (Fig. 2). For example, in a study conducted on fish from the coast waters of Portugal, L3 larvae of Anisakis spp. were found in $100 \%$ of the European hake (Merluccius merluccius), $95.6 \%$ of Atlantic mackerel (Scomber scombrus), 93.8\% Blue whiting (Micromesistius poutassou), $75.9 \%$ of the examinated Atlantic horse mackerel (Trachurus trachurus) and $6.8 \%-28.1 \%$ of

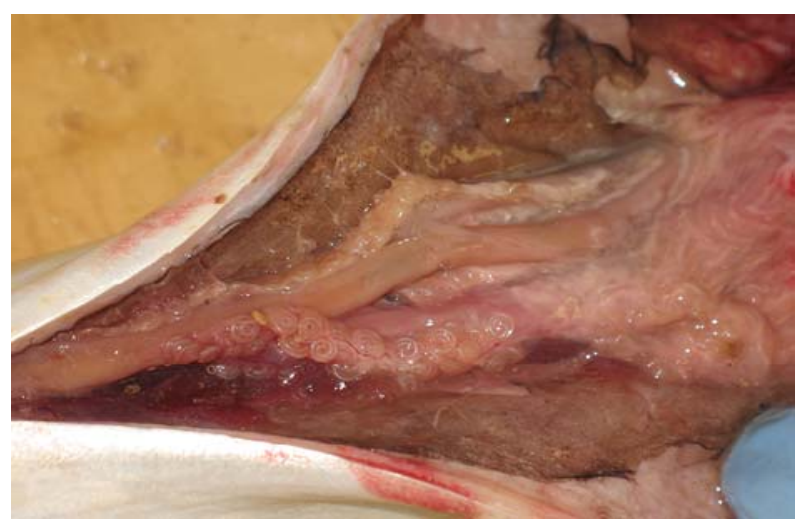

Fig. 1 Larvae of Anisakis spp. in body cavity of mackerel (Scomber scombrus).

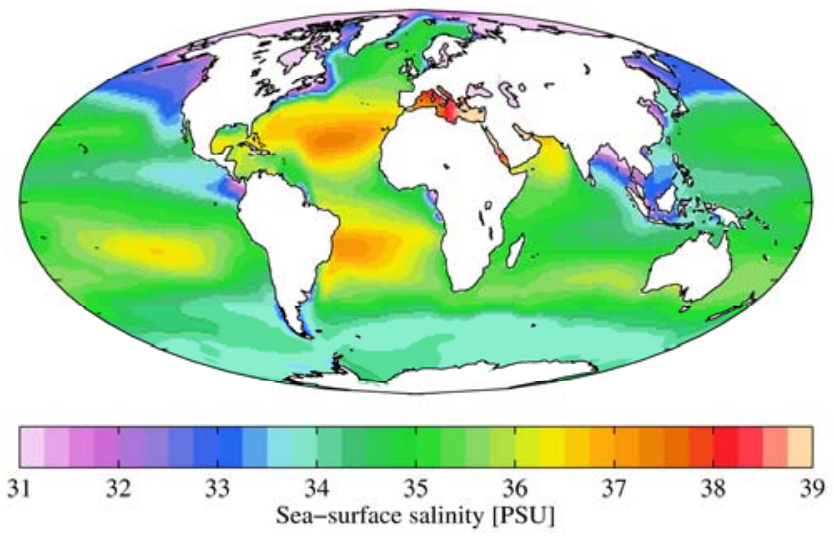

Fig. 2 Sea-surface salinity.

Data was from the World Ocean Atlas 2009. 
Table 1 Occurrence of Anisakis simplex in wild and farmed marine fish (FAO).

\begin{tabular}{llll}
\hline Fish & Origin & Number of samples & \% of infected samples \\
\hline Farmed salmon & Washington & 50 & 0 \\
Farmed salmon & Norway & 2,832 & 0 \\
Farmed salmon & Scotland & 867 & 0 \\
Farmed coho salmon & Japan & 249 & 0 \\
Farmed rainbow trout & Japan & 40 & 0 \\
Wild salmon & Washington & 237 & 100 \\
Wild salmon & North Atlantic & 62 & 65 \\
Wild salmon & West Atlantic & 334 & $80-100$ \\
Wild salmon & East Atlantic & 34 & 82 \\
Wild coho salmon & Japan & 40 & 100 \\
Sardines & Mediterranean & 7 & 14 \\
Herring & Mediterranean & 4,948 & 86 \\
Herring & Pacific Ocean & 127 & 88 \\
Cod & Pacific Ocean & 509 & 84 \\
\hline
\end{tabular}

the fish species, such Black seabream (Spondyliosoma cantharus), Pout whiting (Trisopterus luscus), Sole (Solea spp.), gurnard (Trigla lucerna) and European pilchard (Sardina pilchardus). Anisakis spp. larvae weren't detected in Wedge sole (Dicologoglossa cuneata) and Shore rockling (Gaidropsarus mediterraneus) [14]. Research conducted on fish from the coast of Norway found Anisakis spp. larvae in the peritoneum of $99.6 \%$ coalfish (Pollachius virens), 97.8\% of Atlantic cod (Gadus morhua) and 88\% redfish (Sebastes marinus) [15]. Similar studies conducted on the coast of Spain showed the presence of Anisakis simplex s.s. larvae and Anisakis pegreffii in 14 fish species, like Blue shark (Prionace glauca), Conger (Conger conger), Garfish (Belone belone), European hake (Merluccius merluccius), Blue whiting (Micromesistius poutassou), Blue ling (Molva dypterygia), Pout whiting (Trisopterus luscus), Frog-fish (Lophius piscatorius), Atlantic mackerel (Scomber scombrus), Black seabream (Spondyliosoma cantharus), Atlantic horse mackerel (Trachurus trachurus), Four-spot megrim (Lepidorhombus boscii), Grey gurnard (Eutrigla gurnardus) and Red scorpion fish (Scorpaena scrofa). Extensivity of invasion of Anisakis spp. determined by the presence of larvae in a body cavity and organs of these species was from $32 \%$ to $100 \%$. Furthermore, in the European hake,
Blue whiting, Frog-fish, Atlantic mackerel, Atlantic horse mackerel, Anisakis simplex s.s. larvae and Anisakis pegreffii were detected in muscle of $3.2 \%-41.1 \%$ fish tested [11]. The results of the project carried out on fish harbored on Southern Baltic Sea (more than 30,000 Herring, over 3,000 Atlantic cod, over 1,500 Flounders and 3,400 Sprats) showed that the parasites belonging to Anisakidae were most common in Herrings $(0 \%-86 \%)$ and Atlantic cods (4\%). In Sprats, there were no larvae of these parasites [16].

Detection of Anisakis spp. larvae into the peritoneum or other internal organs in freshly caught fish is common. In muscle tissue, larvae are recorded rarely due to the shortage of necessary time to transfer larvae from the peritoneal cavity into the muscle tissue. Anisakis spp. larvae are moving into the muscle tissue only a few hours after the death of fish. Thus early evisceration is so important to prevent anisakiasis. Prolongated time of evisceration highly increased the risk of anisakiasis. The internal quality of fish products highly depends on the time of evisceration. For example, cheap products, like smoked Herrings from Lublin hypermarkets, has shown the presence of L3 larvae of Anisakis simplex in $83.3 \%$ of the samples [6]. Szostakowska et al. [16] also reported the presence of Anisakis simplex larvae (live) in the 
pickled and frozen Herring.

\section{Anisakiasis in Human}

Human infection with nematodes of the genus Anisakis are caused by consumption of fish containing live larvae. The larvae locate in humans in the gastrointestinal tract, most commonly in the stomach (gastric form) or the small intestine (intestinal form). Clinical symptoms of gastric anisakiasis usually appear in several hours after ingestion. There are primarily acute abdominal pain, vomiting, diarrhea, and sometimes fever. Gastric form is reported quite often in Japan, while the intestinal infections were more common among natives in Europe [17]. The intestinal form of anisakiasis symptoms do not appear until several days after consumption of infected fish and it is not that strong as in the gastric form. In this form, the larvae penetrate the intestinal mucosa of human. But in this case, they do not produce activation agent of white blood cells, which causes infiltrates in the parasite penetration place. This leads to limited inflammation or necrosis of infected tissue. In this case, only surgery intervention can be successful [18]. Complications may occur and may even lead to peritonitis. Also pharyngeal form of anisakiasis is described; when the nematode penetrates the throat mucosa of infected person, it causes strong coughs and vomiting. Under certain conditions, the larvae can pass through the gastrointestinal mucosa to the pancreas, liver, spleen and lungs, and may develop in intestine into four stages (L4). The larvae passed through the wall of the gastrointestinal tract and often settled on the peritoneum or subcutaneous tissue, causing granulomas or ulcerations [19]. So far, no cases of human anisakiasis have been reported in Poland. However, the problem exists but is likely to be underdiagnosed and/or underreported. The number of hypersensitivity for Anisakis allergens is growing. Anisakis simplex allergens are now considered as the most common among food allergens [20, 21]. Presence of Anisakis allergens can cause hazardous allergic reactions, including anaphylaxis. It has to be pointed that such reactions may also occur after ingestion of processed fish and fishery products containing parasite proteins [22]. It has been proved that Anisakis allergens, in Hake (Merluccius merluccius) tissues infected with Anisakis simplex, were active even after 11 months of freeze storage. Furthermore, this allergen is heat stable and resistant to digestive enzymes. Therefore, in susceptible individuals, hypersensitivity may also occur even after consumption of heat-treated fishery products containing dead larvae or their parts. Even a trace amount of the allergen in food may cause the typical allergic reactions. Allergic reactions to food can be produced by contaminants from poultry fed with fishmeal contaminating with Anisakis. Even if fishmeal production process inactivates larvae (high temperature), allergenic factors are still present in final product. Anisakis spp. allergens are resistant to digestive enzymes, and may be present in muscle tissues of farmed chickens for $24 \mathrm{~h}$ after ingestion of fishmeal [5, 23-28].

\section{Treatment}

So far, the only effective treatment of anisakiasis is endoscopic or surgical removal of the living parasites. Usually, larvae are dying about three weeks after infection. If they do not induce any clinical symptoms, removing surgery is not necessary. However, when it comes to the formation of granulomas, ulceration or other pathological changes, the surgical intervention is necessary. For pharmacological treatment, drugs like albendazole and mebendazole, are commonly used; however, their effectiveness is discussed. Treatment with albendazole reduces the number of larvae, however the effectiveness of the drug decreases in low $\mathrm{pH}[29]$.

There are different factors influencing anisakiasis. For example, lower number of anisakisis is observed in some Asian societies consuming raw fish with spices, such as ginger or perilla. That phenomenon 
caused interest of scientist. The survey about various essential oils showed that $\alpha$-pinene significantly reduces the damage to the gastrointestinal mucosa of infected rats [30]. In contrast, Hierro et al. [31] have shown that substances, such as perillaldehyde, citral and citronellol, damage Anisakis spp. L3 larvae, and thereby they reduce the bleeding in the digestive tract of experimentally infected rats. However, the results of those studies were not transfered to medicine. The best prevention against anisakiasis is consumers' education programme and the recommendation to avoid eating raw or partially cooked marine fish or squid [32].

\section{Conclusions}

The invasion of nematode of the Anisakidae family poses a high risk to human health, especially among groups where raw fish is consumed traditionally or occasionally as modern exotic food. The risk of infection is multiplied by traveling especially to Asia and consumption of local specialities made with raw fish. In Europe, raw products like sushi become more and more popular and it seems to be the real threat. The current legislation rules protect consumers from the Anisakis infection. In accordance to European Union Regulation (EC) No 853/2004, fish and fish products must be subjected to freezing temperatures not higher than $-20^{\circ} \mathrm{C}$ in all parts of the product and being kept in that temperature not less than $24 \mathrm{~h}$. This also applies to raw eaten fish and partially cooked, cold smoked, preserved, marinated or slightly salted fish, especially species like Herring, Mackerel, Sprat, Atlantic and Pacific Salmon. However, durable and resistant temperature of $A$. simplex allergens is so high that the problem of allergies remains unresolved.

\section{References}

[1] Grabda, J. 1981. Parasitological Manual of Sea Fish. Warszawa, Polish: PWN. (in Polish)

[2] Grabda, J. 1991. Marine Fish Parasitology. Warszawa, Polish: PWN.

[3] Grabda-Kazubska, B., and Okulewicz, A. 2005. "Fish Parasites." Warszawa, Polish: Polish Parasitological
Society. (in Polish)

[4] Mattiucci, S., and Nascetti, G. 2006. "Molecular Systematics, Phylogeny and Ecology of Anisakid Nematodes of the Genus Anisakis Dujardin, 1845: An Update." Parasite 13 (2): 99-113.

[5] Lorenzo, S., Iglesias, R., Leiro, J., and Ubiera, F. M. 2000. "Usefulness of Currently Available Methods for the Diagnosis of Anisakis simplex Allergy." Allergy 55 (7): 627-33.

[6] Guz, L., Studzińska, M. B., Sadzikowski, A. B., and Gundłach, J. L. 2005. "Anisakiasis." Annales Universitatis Mariae Curie-Skłodowska 60 (10): 74-87. (in Polish)

[7] Brattey, J. 1995. "Identification of Larval Contracaecum osculatum s.l. and Phocascaris sp. (Nematoda: Ascaridoidea) from Marine Fishes by Allozyme Electrophoresis and Discriminant Function Analysis of Morphometric Data." Canadian Journal of Fisheries and Aquatic Sciences 52: 116-28.

[8] Pontes, T., D’Amelio, S., Costa, G., and Paggi, L. 2005. "Molecular Characterization of Larval Anisakid Nematodes from Marine Fishes of Madeira by a PCR-Based Approach, with Evidence for a New Species.” J. Parasitol. 91 (6): 1430-4.

[9] D'Amelio, S. 2014. "Risk of Anisakidosis Related to Fish Consumption." Accessed February 1, 2015. http://www.iss.it/binary/crlp/cont/ANISAKIDOSIS_D\%2 7AMELIO.1190297568.pdf.

[10] Yubero, F. J. R., Auroux, F. J. A., and Lopez, V. 2004. "Anisakid Parasites in Commercial Fish." Anales de la Real Academia Nacional de Ciencias Veterinarias de Andalucia Oriental 17: 173-96. (in Polish)

[11] Abollo, E., Gestal, C., and Pascual, S. 2001. “Anisakis Infestation in Marine Fish and Cephalopods from Galician Waters: An Updated Perspective." Parasitol. Res. 87 (6): 492-9.

[12] Rolbiecki, L., and Rokicki, J. 2000. "The Occurrence of the Nematodes Anisakis simplex Pathogenic to Man in Pike-Perch from the Vistula Lagoon, Poland." Wiadomosci Parazytologiczne 46 (3): 397-402.

[13] FAO. "Assessment and Management of Seafood Safety and Quality." Fisheries and Aquaculture Department. Accessed February 1, 2015. http://www.fao.org/docrep/006/y4743e/y4743e0c.htm.

[14] Silva, M. E. R., and Eiras, J. C. 2003. "Occurrence of Anisakis sp. in Fishes off the Portuguese West Coast and Evaluation of Its Zoonotic Potential.” Bull. Eur. Ass. Fish Pathol. 23: 13-7.

[15] Stromnes, E., and Andersen, K. 1998. "Distribution of Whaleworm (Anisakis simplex, Nematoda, Ascaridoidea) L3 Larvae in Three Species of Marine Fish: Saithe (Pollachius virens (L.)), Cod (Gadus morhua L.) and 
Redfish (Sebastes marinus (L.)) from Norwegian Waters." Parasitol. Res. 84 (4): 281-5.

[16] Szostakowska, B., Myjak, P., Wyszyński, M., Pietkiewicz, H., and Rokicki, J. 2005. "Prevalence of Anisakin Nematodes in Fish from Southern Baltic Sea." Pol. J. Microbiol. 54: 41-5.

[17] Hochberg, N. S., and Hamer, D. H. 2010. "Anisakidosis: Perils of the Deep.” Clin. Infect. Dis. 51 (7): 806-12.

[18] Danek, K., and Rogala, B. 2005. "Anisakis simplex-Ukryty Allergen Ryb." Alergia Astma Immunologia 10 (1): 1-5.

[19] Acha, P. N., and Szyfres, B. 1987. Zoonoses and Communicable Diseases Man and Animals. Washington, D.C.: Pan American Health Organization (PAHO).

[20] Anibarro, B., Seoane, F. J., and Mugica, M. V. 2007. "Involvement of Hidden Allergens in Food Allergic Reactions." J. Invest. Allergol. Clin. Immunol. 17: 168-72.

[21] Kochanowski, M., Karamon, J., Dąbrowska, J., Cencek, T., Bilska-Zając, E., and Różycki, M. 2013. "Hypersensitivity for Anisakis simplex Allergens." Życie Weterynaryjne 88 (8): 663-5. (in Polish)

[22] Audicana, L., Audicana, M. T., Fernandez de Corres, L., and Kennedy, M. W. 1997. "Cooking and Freezing May not Protect against Allergenic Reactions to Ingested Anisakis simplex Antigens in Humans." Vet. Rec. 140 (9): 235.

[23] Armentia, A., Martín-Gil, F. J., Pascual, C., Martín-Esteban, M., and Callejo, A. 2006. "Anisakis simplex Allergy after Eating Chicken Meat." J. Invest. Allergo. Clin. Immunol. 16 (4): 258-63.

[24] Caballero, M. L., and Moneo, I. 2004. "Several Allergens from Anisakis simplex Are Highly Resistant to Heat and Pepsin Treatments." Parasitol. Resp. 93 (3): 248-51.

[25] Gonzalez-Munoz, M., Luque, R., Nauwelaers, F., and
Moneo, I. 2005. "Detection of Anisakis simplex-Induced Basophil Activation by Flow Cytometry." Cytometry B: Clinical Cytometry 68 (1): 31-6.

[26] Moneo, I., Caballero, M. L., Gonzaez-Muñoz, M., and Rodriguez-Mahillo, A. I. 2005. "Isolation of a Heat-Resistant Allergen from the Fish Parasite Anisakis simplex." Parasitol. Resp. 96 (5): 285-9.

[27] Rodríguez-Mahillo, A. I., González-Muñoz, M., Heras, C., Tejada, M., and Moneo, I. 2010. "Quantification of Anisakis simplex Allergens in Fresh, Long-Term Frozen and Cooked Fish Muscle." Foodborne Pathog. Dis. 7 (8): 967-73.

[28] Rodriguez-Mahilloa, A. I., Gonzalez-Muñoza, M., Gomez-Aguadob, F., Rodriguez-Pereza, R., and Corcuerab, M. T. 2000. "Cloning and Characterization of the Anisakis simplex Allergen Ani s 4 as a Cysteine-Protease Inhibitor." International Journal for Parasitology 37 (8-9): 907-17.

[29] Arias-Diaz, J., Zuloaga, J., Vara, E., Balibrea, J., and Balibrea, J. L. 2006. "Efficacy of Albendazole against Anisakis simplex Larvae in Vitro." Dig. Liver Dis. 38 (1): 24-6.

[30] Navarro, M. C., Noguera, M. A., Romero, M. C., Montilla, M. P., and González de Selgas, J. M. 2008. “Anisakis simplex s.l.: Larvicidal Activity of Various Monoterpenic Derivatives of Natural Origin against L3 Larvae in Vitro and in Vivo." Exp. Parasitol. 120 (4): 295-9.

[31] Hierro, I., Valero, A., and Navarro, M. C. 2006. "In Vivo Larvicidal Activity of Monoterpenic Derivatives from Aromatic Plants against L3 Larvae of Anisakis simplex s.1.." Phytomedicine 13 (7): 527-31.

[32] Szkoda, J., Nawrocka, A., and Kmiecik, M. 2014. "Toxic Elements in Free-Living Freshwater Fish, Water and Sediments in Poland." Bulletin of the Veterinary Institute in Pulawy 58 (4): 589-95. 